\title{
Ortner's syndrome: a case report and review of the literature
}

\author{
A R Hurtarte Sandoval, ${ }^{1}$ R Carlos Zamora, ${ }^{2}$ J M Gómez Carrasco, ${ }^{1}$ A Jurado Ramos ${ }^{2}$
}

${ }^{1}$ Department of Nephrology, Reina Sofia Hospital, Córdoba, Spain

${ }^{2}$ Department of Otolaryngology and Head and Neck Surgery Service, Reina Sofia Hospital, Córdoba, Spain

Correspondence to Dr A R Hurtarte Sandoval, aldohurtarte12@hotmail.com

Accepted 29 June 2014

\section{SUMMARY}

We present a case of a 67-year-old man who was an active smoker, with a clinical history of ischaemic cardiopathy, hypertension, who presented to the emergency room with hoarseness of voice of 2 weeks duration. No other neurological or cardiorespiratory symptoms were found. Physical examination revealed an aortic regurgitation murmur with radial pulse difference between the upper limbs and femoral pulse difference on lower limbs. Laryngoscopy examination revealed a left vocal cord paralysis in the paramedian position, without signs of malignancy. Thoracoabdominal CT angiography was performed to rule out an aortic dissection. CT revealed a dissection in the descending thoracic aortic arch and abdominal aorta. Cardiovascular surgery was consulted and decided to place endoprosthesis at the thoracic and abdominal aortic area. Hoarseness eventually resolved during the following weeks. Ortner's syndrome is described as hoarseness of voice caused by compression of the left recurrent laryngeal nerve of cardiovascular origin.

\section{BACKGROUND}

Ortner's syndrome or cardiovocal syndrome was described by Norbert Ortner. He described it in a mitral stenosis with left atrial enlargement that compressed the left recurrent laryngeal nerve. ${ }^{1}$ Incidence of this syndrome in relation with left atrial enlargement is reported to be around 0.6$5 \%$. $^{2}$ As time passed, other cardiovascular causes were included and described in this case report and literature review. Recently hoarseness in this syndrome has been described to be due to compression of the left recurrent laryngeal between the left pulmonary artery and the aorta at the ligamentum arteriosum. ${ }^{3}$ It has also been described in patients with pulmonary hypertension, aortic aneurysm, cardiac abnormalities, chronic obstructive pulmonary disease, ${ }^{4}$ recurrent pulmonary emboli, ${ }^{5}$ etc. Around $10 \%$ of aortic dissections are asymptomatic and very few cases have been reported in the literature to debut with Ortner's syndrome. ${ }^{6}$

It is important to acknowledge this syndrome in the clinical practice, since the suspicion can greatly influence the patient's outcome. Patients usually have hoarseness, which leads them to the otolaryngologist for evaluation. Medical and surgical management depend greatly on the nerve damage and patient comorbidity.

\section{CASE PRESENTATION}

A 67-year-old man with a medical history of ischaemic heart disease with coronary triple bypass performed 29 years ago, hypertension, right common iliac stent placement in 2008, type 2 diabetes mellitus treated with insulin, morbid obesity, and a 40 pack-year smoking history; presented to the emergency room with hoarseness of voice of 2 weeks duration. No other neurological symptoms were found, and the patient denied any cardiorespiratory symptoms. On physical examination, blood pressure was $210 / 70 \mathrm{~mm} \mathrm{Hg}$ on the right arm and $200 / 70 \mathrm{~mm} \mathrm{Hg}$ on the left arm; left lower limb had a blood pressure of $195 / 70 \mathrm{~mm} \mathrm{Hg}$; left heart rate was $88 \mathrm{bpm}$ and a $\mathrm{SO}_{2}$ of $97 \%$. Neck inspection and palpation documented a normal thyroid gland, no masses or enlarged lymph nodes. Cardiopulmonary examination revealed an early diastolic aortic murmur grade IV/VI; strong, quick pulse and an increased blood pressure difference between upper and lower limbs (Hill's sign). The otolaryngologist performed laryngeal examination that revealed a left vocal cord paralysis in the paramedian position, and no malignancy was suspected.

\section{INVESTIGATIONS}

Laboratory results were as follows: white cell count $6.240 \times 10^{9} / \mathrm{L}$, haemoglobin $12.40 \mathrm{~g} / \mathrm{dL}$, haematocrit $31.20 \%$, platelets $263000 \times 10^{9} / \mathrm{L}$, glucose $167 \mathrm{mg} / \mathrm{dL}$, urea $49 \mathrm{mg} / \mathrm{dL}$, creatinine $1.1 \mathrm{mg} / \mathrm{dL}$; sodium $140 \mathrm{mmol} / \mathrm{L}$, potassium $3.70 \mathrm{mmol} / \mathrm{L}$, chloride $102 \mathrm{mmol} / \mathrm{L}$, magnesium $1.9 \mathrm{mg} / \mathrm{dL}$, bicarbonate $25 \mathrm{mEq} / \mathrm{L}$ and liver function tests were within normal ranges. ECG showed normal sinus rhythm with left ventricular enlargement. Chest radiograph showed cardiomegaly, and lung fields were normal. Echocardiogram was performed with technical difficulty due to patient's body habitus, revealing a moderate left ventricular systolic dysfunction, mild mitral and aortic regurgitation, with an ejection fraction of $45 \%$. Right cavities appeared normal and no other findings were relevant. Thoracoabdominal CT angiography was performed because of an aortic dissection suspicion. CT revealed a dissection in the descending thoracic aortic arch, $1 \mathrm{~cm}$ distal to the left subclavian artery, with an important evidence of a transmural ulcer of about $3 \times 4 \mathrm{~cm}$ in diameter, in contact with the left pulmonary artery (figure 1A-D). Likewise, beneath the right renal artery, a haematoma was visualised. The haematoma caused an aortic stenosis that extended to the left iliac artery (figure 2A, B).

\section{DIFFERENTIAL DIAGNOSIS}

- Thyroid neoplasms

- Oesophageal neoplasms 


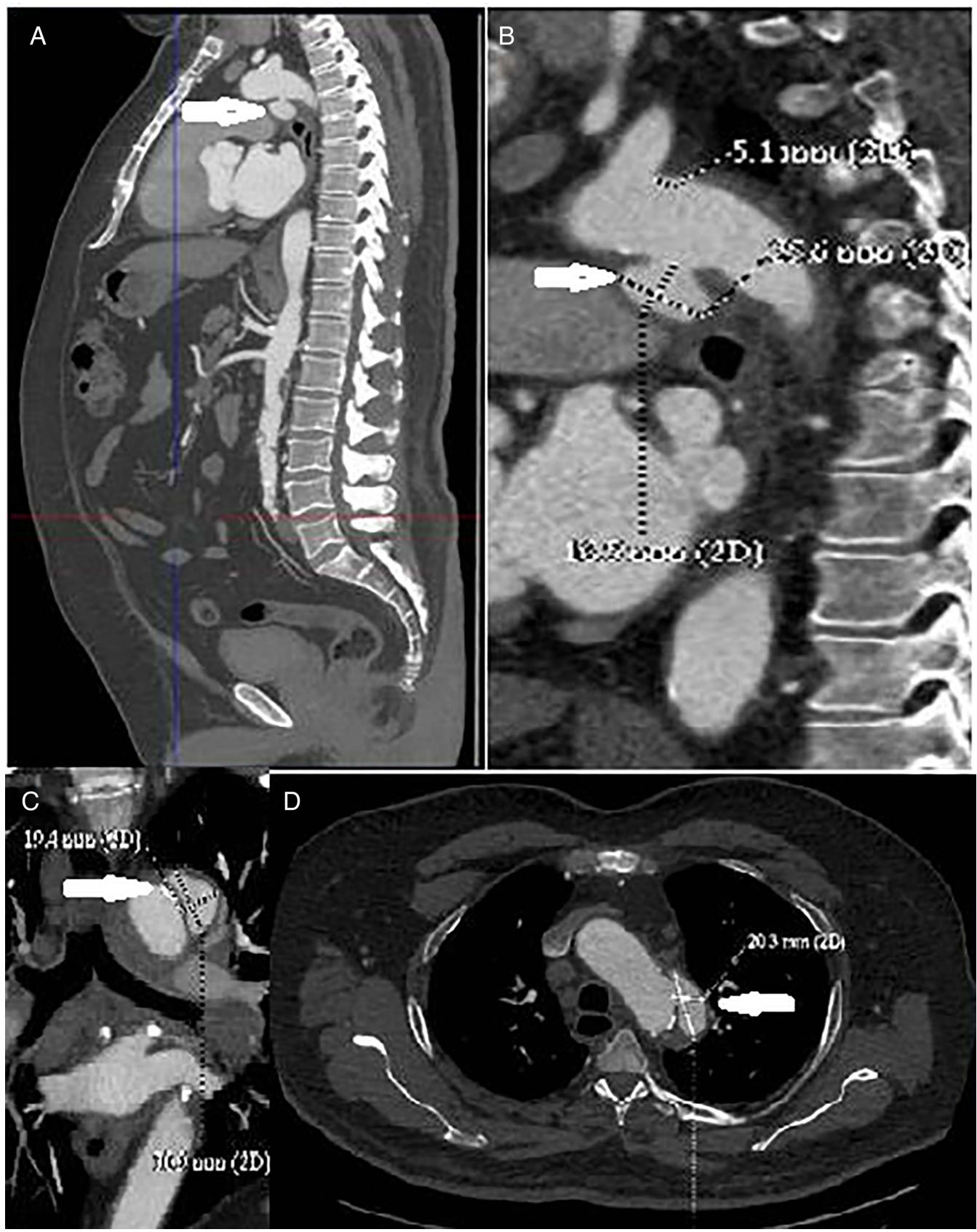

Figure 1 (A-D) Dissection in the descending thoracic aortic arch, $1 \mathrm{~cm}$ distal to the left subclavian artery, with an important evidence of a transmural ulcer of about $3 \times 4 \mathrm{~cm}$ in diameter, in contact with the left pulmonary artery.

- Lung neoplasm

- Mediastinal neoplasms

- Surgical iatrogenic injuries

\section{TREATMENT}

Cardiovascular surgery department was consulted for urgent surgery. A bypass in the left subclavian artery and the ileofemoral artery are placed. No complications were reported.

\section{OUTCOME AND FOLLOW-UP}

After surgery the patient developed acute renal failure with anuria. Renal $\gamma$ graphy revealed no vascular damage. Initially, the nephrology team decided to initiate haemodialysis by temporary femoral access which was later changed to permanent right subclavian artery; without recovery of renal function. Hoarseness resolved a few weeks after surgery.

\section{DISCUSSION}

Left recurrent laryngeal nerve (LRLN) palsy is much more frequent than right laryngeal nerve palsy. Most vocal cord paralysis is due to neoplasia, followed by iatrogenic procedures. Aortic aneurysm causing laryngeal nerve palsy is reported to be around $0.3 \%$ in some series.

In aortic dissection, thoracic pain is usually referred to the back or abdominal area, which suggests extension of the dissection. Neurological symptoms can be seen, mainly stroke, due to the involvement of the carotid arteries in $20-30 \%$ of the cases. ${ }^{8}$ Other symptoms include syncope, arterial hypotension, 
Figure 2 (A) Abdominal aortic dissection that extends to the left common iliac artery with an aneurysm dilation and mural thrombosis.

A permeable stent is seen in the right common iliac artery. (B) The arrow demonstrates the intimal flap in relation with the abdominal aortic dissection.

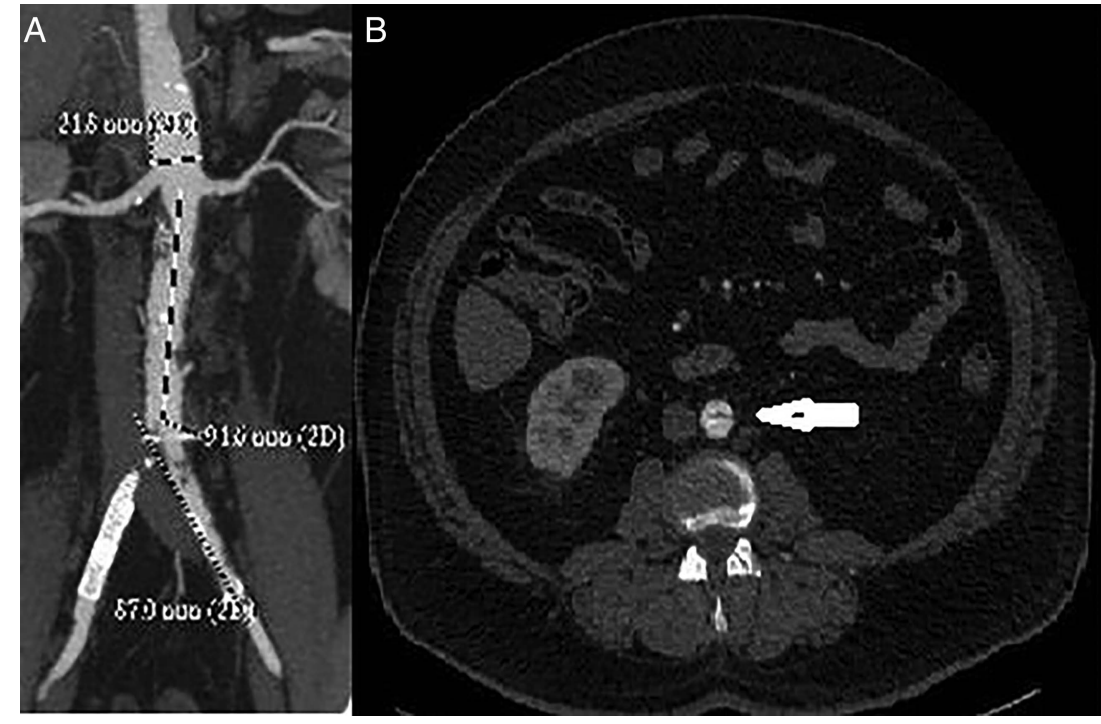

transverse myelopathy, anterior spinal syndrome, quadriplegia, paraplegia. $^{9-11}$

Risk factors that predispose to aortic dissection are arterial hypertension, Marfan syndrome, aortic dilation, coarctation of aorta, annuloaortic ectasia, aortic arch hypoplasia, pregnancy, etc. Aortic involvement in connective tissue disorders can also predispose to aortic dissection. ${ }^{6}$

LRLN palsy in aortic dissection is caused by direct pressure of the underlying haematoma at the thoracic segment of the nerve. ${ }^{6}$ It is rare to see hoarseness due to cardiovascular features, but if detected in time the patient may gain great benefits.

The clinical features of LRLN palsy in laryngoscopy can be viewed as an asymmetric vocal fold while speaking; the left vocal fold could be viewed in a paramedian position and as an incomplete glottis closure. The affected area tends to be shorter while mobilising, and the arytenoid can be seen in an anterior rotation. $^{12}$

Symptoms include hoarseness, dysphagia and breathing difficulties due to an incomplete glottic closure.

The main surgical approach for unilateral vocal cord paralysis is medialisation of the affected vocal fold, in which ideal time of approach is still being discussed. The injection medialisation approach uses a variety of substances that permit the medialisation of the affected vocal fold. All encountered data in the literature of different studies shows a voice improvement outcome. Hyaluron, fat, collagen, silicone and other material have been used, fat being the most used. Hyaluron and silicone have been reported to cause more local rejection than other materials. Complications are rare and some opt to do it in the awake patient. Stridor, dysphonia after injection and the need for orotracheal tube placement have been reported, due to overinjection or subepithelial placement. It is important to take special care not to place the injection in a superficial manner. ${ }^{12}$ In general, vocal fold should be injected at the vocal process level and the transition zone from the superior surface of the vocal fold to the ventricle. Injection can then be performed observing vocal fold position, size and glottic closure. ${ }^{13}$

Medialisation thyroplasty has a long lasting approach that repositions the affected vocal fold that uses thyroid cartilage and alloplastic material. Overnight observation depends on patients comorbidities. The different material used can be with carved silastic implant with a level 2 evidence.

Laryngeal reinnervation is another interesting approach to unilateral vocal fold paralysis. This technique uses the vicinity of nerves near the affected vocal fold. Under expert surgeons, complications are rare.

In the short-term, injection medialisation can achieve comparable clinical results as medialisation thyroplasty. Thyroplasty and reinnervation also achieve comparable voice outcomes (evidence grade $\mathrm{B}) .^{12}$

The majority of patients with Ortner's syndrome secondary to aortic dissection reported in the literature have many comorbidities and conservative treatment was the treatment of choice. In these patients no aortic endoprosthesis was placed, however, hoarseness of voice persisted. Our patient's voice hoarseness resolved 3 weeks after abdominal and thoracic aortic endoprosthesis was placed. Current cases and English literature report that LRLN paralysis can recover after 8-12 months, depending on the degree and duration of nerve compression. According to other articles cited, the greater the aneurysm class, the greater the nerve damage and the more difficult to observe a recovery. ${ }^{1415}$

\section{Learning points}

Very few cases of asymptomatic aortic dissection presenting with Ortner's syndrome are reported. It is important to take this identity into account when exploring left unilateral vocal fold paralysis, since an early detection can have a great impact in the clinical outcome of the patient. As always, neoplasia and other more common causes must be ruled out first.

- Patients with a high surgical risk for aortic prosthesis insertion, have other alternative management such as injection medialisation. Patients can undergo voice therapy, but it is not sufficient and not recommended as a monotherapy. Different medialisation techniques (injection, thyroplasty and reinnervation) are used, and comparable outcomes are reported with an evidence grade B.

- Reported cases with Ortner's syndrome secondary to aortic dissection that are surgically managed with an aortic prosthesis substitution have over time spontaneously resolved without other interventions. This depends on the nerve damage encountered. If there is a complete dissection of the nerve, the only approach has to be surgical intervention. 
If 1 year has passed of persistent LRLN paralysis after cardiovascular surgery has been performed, it is recommended to have a medialisation modality. Each case has to be individualised accordingly. Patient's risk factors should be taken into account before surgical intervention, especially cardiovascularly affected patients. Comorbidity plays an important role in prognosis. For instance, if there is a high risk mortality rate for surgical intervention, then a non-surgical approach can be performed. Very few cases report a favourable outcome when applying surgical options for LRLN on patients with Ortner's syndrome, probably due to comorbidity. The majority of cases reported on Ortner's syndrome had a conservative approach even after voice quality improvement. $^{1617}$

Acknowledgements The author would like to thank Dr Pedro Aljama García, Dr Gretsy R and Quintana Sánchez.

Competing interests None.

Patient consent Obtained.

Provenance and peer review Not commissioned; externally peer reviewed.

\section{REFERENCES}

1 Ortner N. Recurrenslähmung bei Mitralstenose. Wien Klin Wochenschr 1897; 10:753-5.

2 Solanki SV, Yajnik VH. Ortneŕs syndrome. Indian Heart J 1972;24:43-6.

3 Sengupta A, Dubey SP, Chaudhuri D, et al. Ortner's syndrome revisited. I Laryngol Otol 1998;112:377-9.
4 Iwashita Y, Sakurai K, Kanaya T. A case of Ortner syndrome. Intern Med 2012;51:1441.

5 Albertini RE. Vocal cord paralysis associated with pulmonary emboli. Chest 1972;62:508-10.

6 Khan IA, Wattanasauwan N, Ansari AW. Painless aortic dissection presenting as hoarseness of voice: cardiovocal syndrome: Ortner's syndrome. Am J Emerg Med 1999:17:361-3.

7 Rosenthal LH, Benninger MS, Deeb RH. Vocal fold immobility: a longitudinal analysis of etiology over 20 years. Laryngoscope 2007;117:1864-70.

8 Rovida A, Povhe B. Cardiovocal syndrome in an infant with double outlet of the right ventricular. Eur J Pediatr 1988;148:15-16.

9 Holloway SF, Fayad PB, Kalb RG, et al. Painless aortic dissection presenting as myelopathy. J Neurol Sci 1993;120:141-4.

10 Greenwood WR, Robinson MD. Painless dissection of the thoracic aorta. Am J Emerg Med 1986;4:330-3.

11 Krishnamurty P, Chandrasekaran K, Rodríguez Vega JR, et al. Acute thoracic aortic occlusion resulting from complex aortic dissection and presenting as paraplejia. J Thorac Imaging 1994;9:101-4.

12 Misono S, Merati AL. Evaluation and management of unilateral vocal fold paralysis. Otolaryngol Clin North Am 2012;45:1083-108.

13 Rosen CA, Blake C. Operative techniques in laryngology. Berlin, Heidelberg: Springer-Verlag, 2008:197-8.

14 Ohki M. Thoracic saccular aortic aneurysm presenting with recurrent laryngeal nerve palsy prior to aneurysm rupture: a prodrome of thoracic aneurysm rupture? Case Rep Otolaryngol 2012;2012:367873.

15 Teixido MT, Leonetti JP. Recurrent laryngeal nerve paralysis associated with thoracic aortic aneurysm. Otolaryngol Head Neck Surg 1990;102:140-4.

16 Monwarul Islam AK, Zaman S, Doza F. Ortner syndrome due to concomitant mitral stenosis and bronchiectasis. Korean Circ J 2012;42:507-10.

17 Prada-Delgado O, Barge-Caballero E. Ortner's syndrome. N Engl J Med 2011;365:939.

Copyright 2014 BMJ Publishing Group. All rights reserved. For permission to reuse any of this content visit http://group.bmj.com/group/rights-licensing/permissions.

BMJ Case Report Fellows may re-use this article for personal use and teaching without any further permission.

Become a Fellow of BMJ Case Reports today and you can:

- Submit as many cases as you like

- Enjoy fast sympathetic peer review and rapid publication of accepted articles

- Access all the published articles

- Re-use any of the published material for personal use and teaching without further permission

For information on Institutional Fellowships contact consortiasales@bmjgroup.com

Visit casereports.bmj.com for more articles like this and to become a Fellow 